\title{
Using Airborne Gamma-Ray Spectrometry for Mapping Radioactive Zones in G. Kadabora Area, Central Eastern Desert, Egypt
}

\author{
Hatem Aboelkhair ${ }^{1}$, Gehad M. Saleh ${ }^{* 2}$, El Sayed Selim ${ }^{1}$ and Asmaa N. Mogahed ${ }^{1}$ \\ ${ }^{1}$ Damietta University, Faculty of Science, Geology Department, P.O. Box 3417 New Damietta, Egypt. \\ ${ }^{2}$ Nuclear Materials Authority, P.O. Box 530, El Maadi, Cairo, Egypt.
}

*Corresponding Authors: Gehad M. Saleh, Nuclear Materials Authority, P.O. Box 530, El Maadi, Cairo, Egypt.

\begin{abstract}
This research aims at mapping potential radioactive zones in G. kadabora area, Central Eastern Desert, Egypt using airborne gamma-ray spectrometry data. Various processing techniques were applied to delineate potential radioactive zones in the studied area including; False Color Composite (FCC), Principal Component Analysis (PCA) and K-Means classification which represents their robustness in extracting known and potential anomalous areas. The results revealed that the highest radioactivity in the G. Kadabora area, Central Eastern Desert is associated with the central. G. Kadabora pluton which can be subdivided into three parts where the northern part of the pluton is the most promising part. The detailed investigation concluded that radioactivity in the current study area is controlled lithologically and structurally where Pegmatite, Syanogranite and Monzogranite represent the lithological control while $\mathrm{N}$-S structural trend represents the structural control.
\end{abstract}

Keywords: Uranium, Gamma-ray spectrometry, Central Eastern Desert, Granitic rocks, Pegmatite, Airborne radiometric data analysis.

\section{INTRODUCTION}

The basement rocks of the Egyptian Eastern Desert represent the northwestern part of the Pan-African Arabian Nubian shield which mostly comprise igneous and metamorphic rocks assemblages that were originated in the East African Orogeny during the Late Proterozoic to the early Paleozoic time (Stern 1994, Kusky, Abdel Salam et al., 2003).

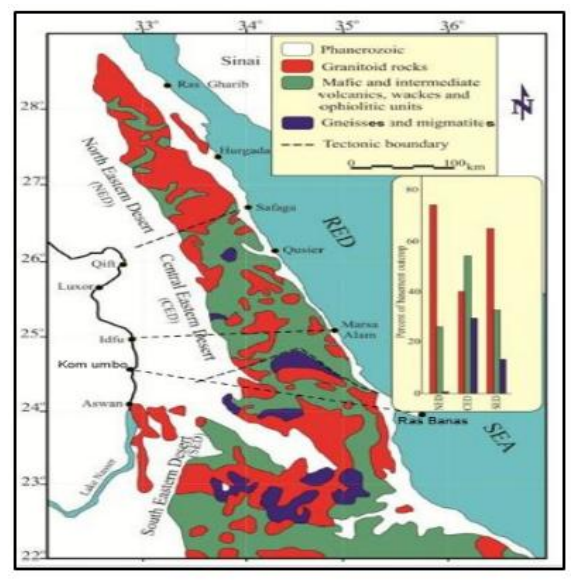

Fig1. Geologic map of the basement complex in the Eastern Desert of Egypt represents the main domains. (Stern and Hedge, 1985).

The basement complex of the Egyptian Eastern Desert has been divided into three domains; Northern Eastern Desert (NED), Central Eastern Desert (CED) and Southern Eastern Desert (SED) (El-Gaby, ElNady et al., 1984, Stern and Hedge 1985). The broad NE- SW trending tectonic zone known as Qena Safaga tectonic discontinuity defines the border between the North Eastern Desert and the Central Eastern Desert while Kom Umbo- Ras Banas Line defines the border between the Central Eastern 
Desert and the Southern Eastern Desert (Stern and Hedge 1985). (EL-Gaby, List et al., 1988) considered the Idfu-Mersa Alam line as the border between the Central Eastern Desert and the Southern Eastern Desert (Fig. 1).

Nuclear Materials Authority (NMA) of Egypt performed comprehensive airborne radiometric exploration programs to search for uranium mineralizations in Egypt during the sixties. This program managed to delineate several radioactive anomalies in the Egyptian Eastern Desert. Most of these anomalies are associated with the younger granites in the basement or to the phosphate beds in the Nubian sedimentary rocks. Through tracing younger granites as a radiometric and lithological control, the (NMA) ground survey discovered several anomalies: Gabal (G.) Gattar, G. El Missikat, G. ElArediya, Wadi (W) Abu Rusheid and G. Um Ara (Fig. 2).

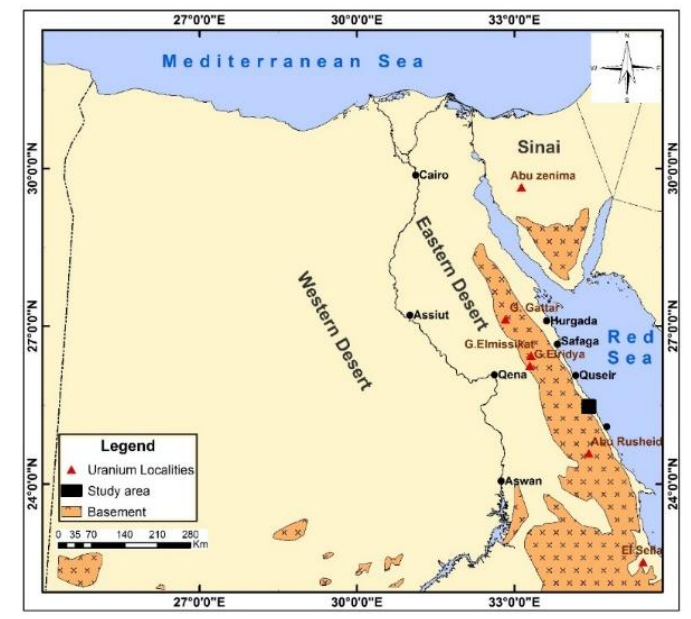

Fig2. Location map of the study area and the uranium occurrences discovered by NMA, Egypt.

Since most radioactive anomalies that were unrevealed by NMA were associated with younger granites so choosing younger granite as a lithological control is the first step toward a successful exploratory research. G. Kadabora granitic pluton is the largest granitic pluton in the Central Eastern Desert which lies next to the red sea coast. Therefore, it catches the attention of the early exploration works as a source for ornamental stones before discovering the radioactive effects on the mineworkers.

The studied area is located at Central Eastern Desert about (11 km) west the Red Sea Coast and ( $3 \mathrm{Km})$ and $(8 \mathrm{Km})$ west the Mersa Alam international airport and Red Sea coastal road respectively. It lies between latitudes $25^{\circ} 21^{\prime} 6^{\prime \prime} \mathrm{N}$ and $25^{\circ} 35^{\prime} 34^{\prime \prime} \mathrm{N}$ and longitudes $34^{\circ} 18^{\prime} 3^{\prime \prime} \mathrm{E}$ and $34^{\circ} 32^{\prime} 19^{\prime \prime} \mathrm{E}$, covering an approximate area of $623 \mathrm{Km}^{2}$ (Fig. 2).

\section{Geological SETTing}

As a part of Central Eastern Desert G. Kadabora area comprises most of the basement igneous and metamorphic rocks exposed in CED except pre pan African gneisses, Dokhan volcanics and Hammamat sediments. (Ahmed 2002) classified rock units in Kadabora area based on field relationships, lithology and structural setting into the following rock units from the oldest to the youngest (Fig. 3):

6- Miocene sediments.

5- Post Granitic dykes (Pegmatite bodies and Quartz veins).

4- Younger Granitoids (Monzogranites, Syanogranites).

3- Older Granitoids (Tonalites to Granodiorites).

----Arc Assemblage----

2- Arc-metavolcanics and volcanogenic metasediments

---Ophiolitic assemblage----

Ophiolitic mélange.

- Matrix (hornblende - biotite and graphitic schists and metagreywackes).

- Blocks and fragments (Pillow lavas, sheeted dykes, Metagabbros, Serpentinites and related rocks). 


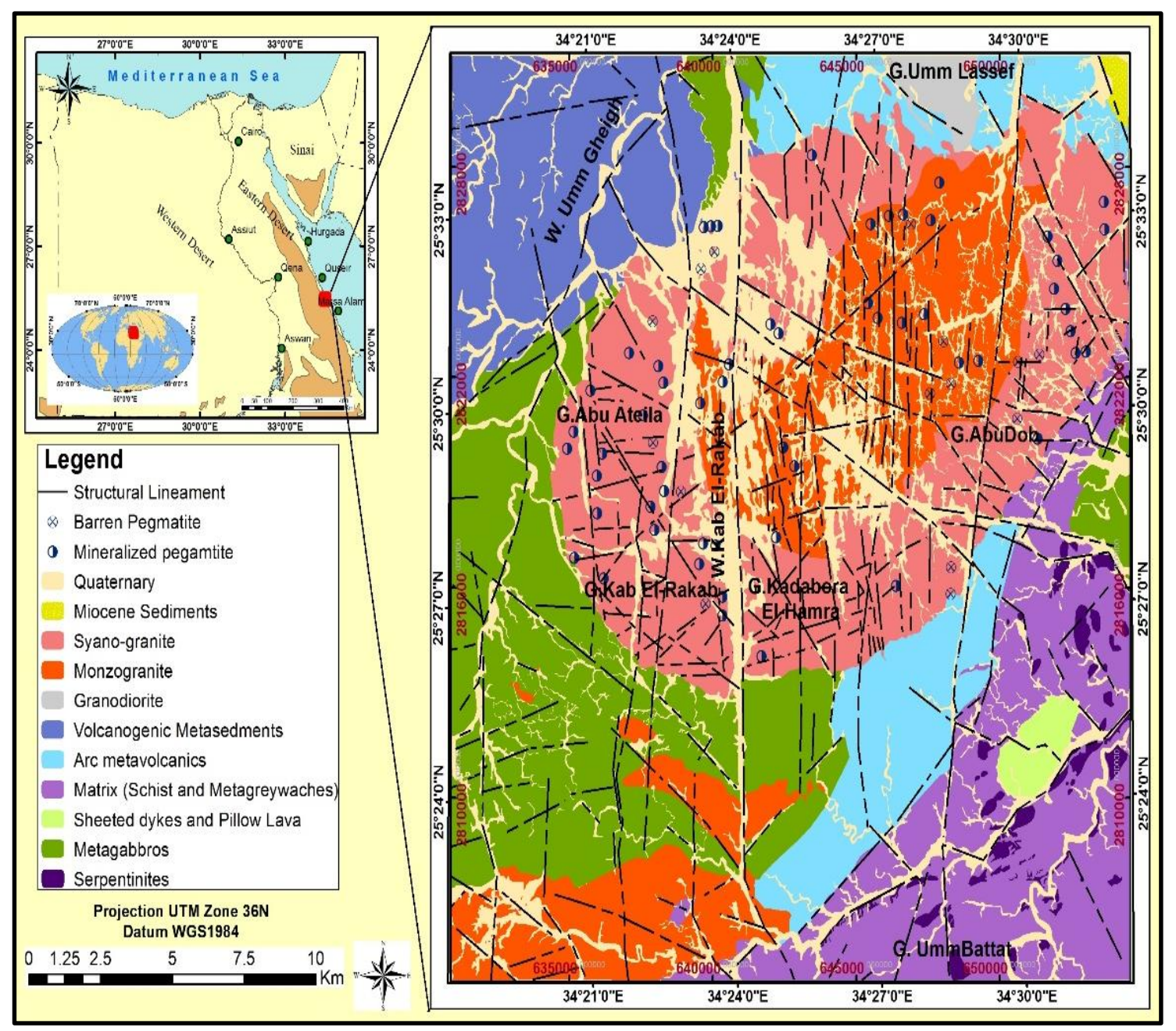

Fig3. Geological map of G. Kadabora area, Central Eastern Desert, Egypt (after Ahmed 2002).

\section{METHODOLOGY}

\subsection{Data}

Airborne Gamma-ray spectrometry has been used efficiently in support of geological mapping and mineral exploration since the 1970s. It represents a valuable tool in mapping granites and associated alterations. It depends on measuring gamma radiation that emits from the unstable nucleus after alpha or beta decay with a distinctive energy intensity of the parent nucleus as each radioactive nucleus has a unique radioactive fingerprint. Three windows are used to measure the radiation emitted by K40, U238 and Th232 in addition to the fourth window representing total count.

\subsection{Preprocessing}

Before using the recorded airborne gamma-ray data group of corrections. including scattering effects, background effects, atmospheric effects and altitude correction were executed. The data then produced as contoured sheets. The present study area is located on Sheet no 66.

\subsection{Processing}

\section{- Gridding}

The data acquisition system record airborne gamma-ray spectrometric data as an isolated point along the flight line and this form of data are usually not preferred for human usage therefore, the first step after preprocessing is interpolating isolated points to produce a raster image using gridding tool.

The resultant four airborne gamma-ray images can be visualized in several ways using color composite images or individually using the absolute concentrations of each spectrometric channel; total count (Tc in Ur) (Fig. 4), potassium percentage K40 (Fig. 5), Bi214 (equivalent uranium eU) (in ppm) (Fig. 6) and equivalent thorium (T1208) (in ppm) (Fig. 7). 


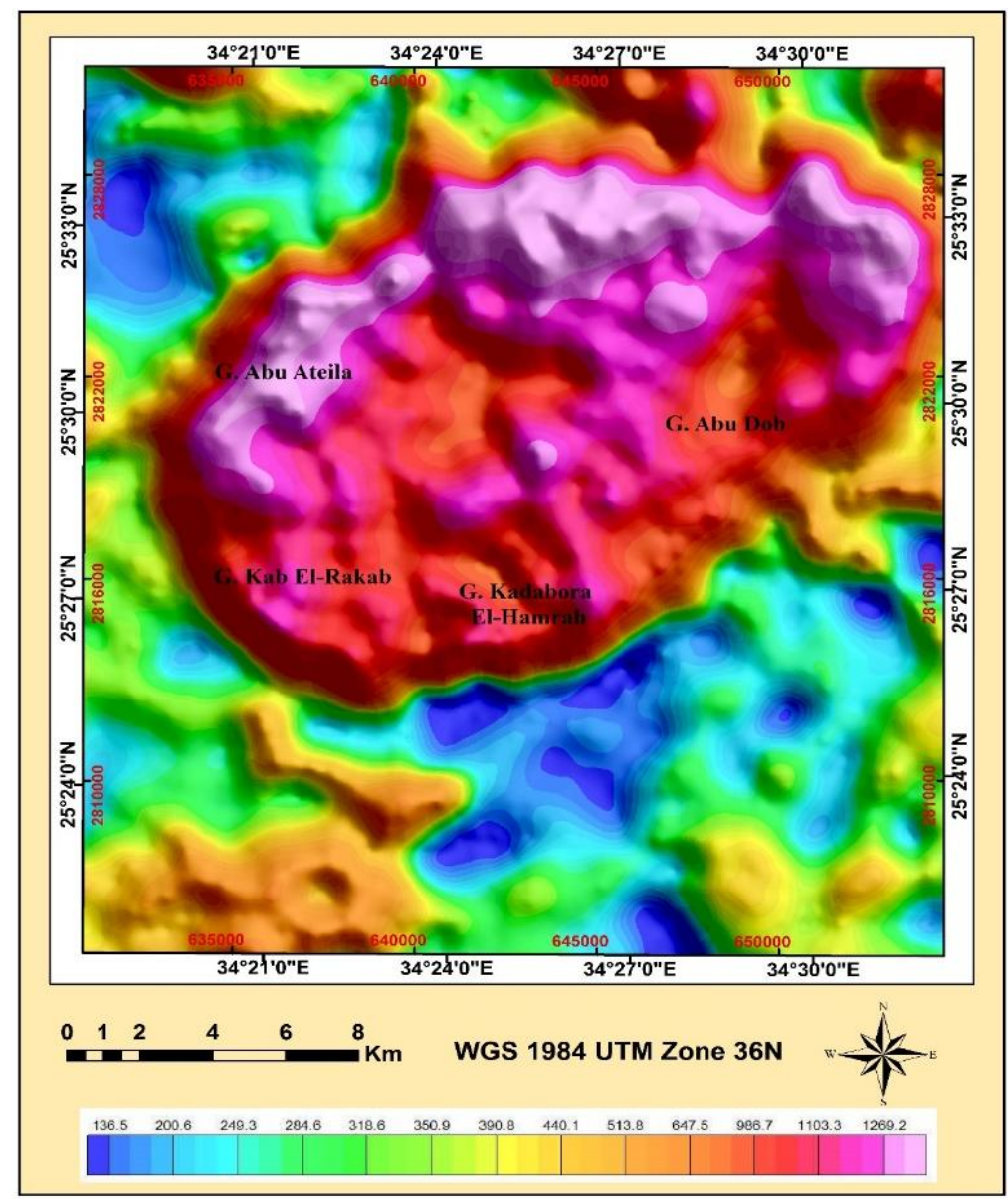

Fig4. Total-count colour shaded map of the studied area, CED, Egypt.(values in UR multiplied by 10)

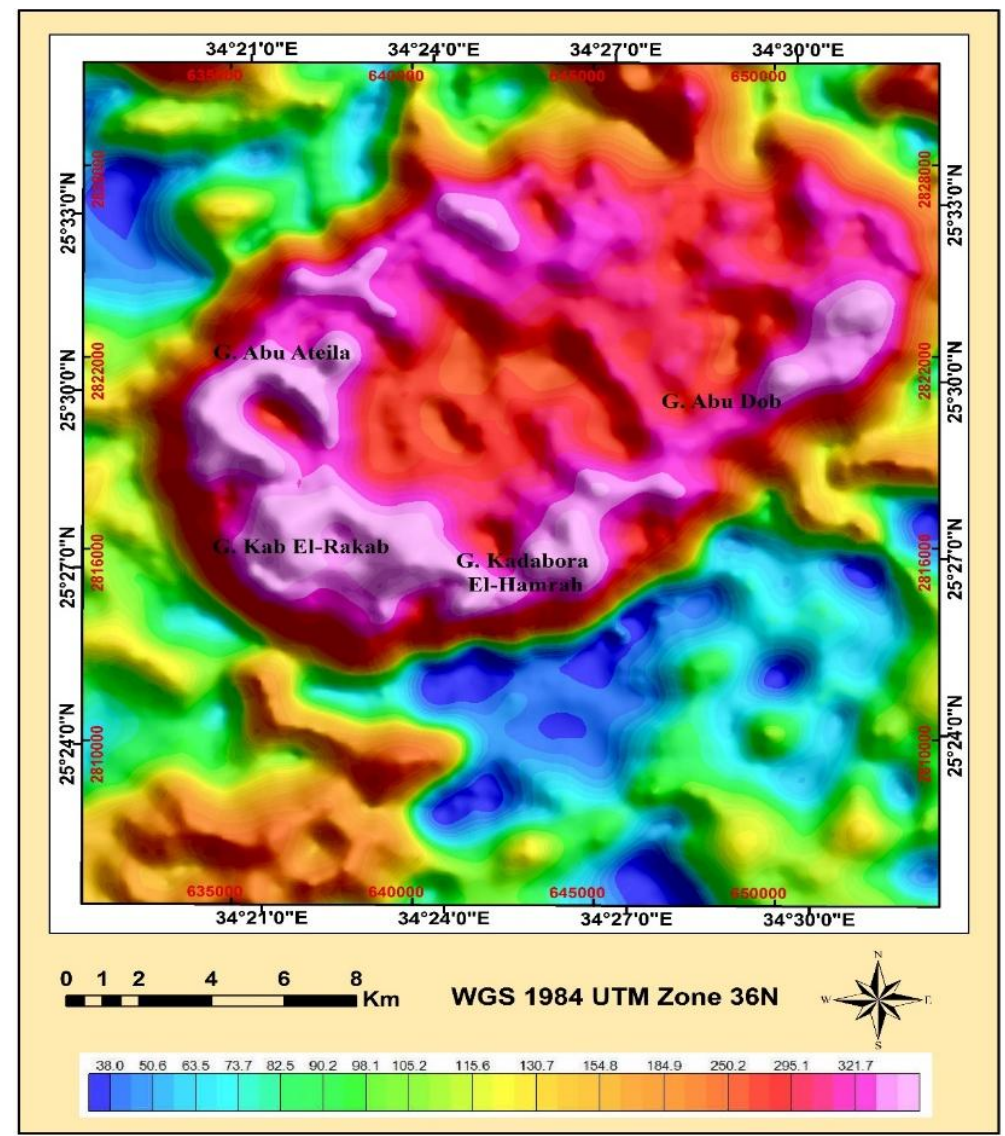

Fig5. Potassium colour shaded map of the studied area, CED, Egypt. (values in \% multiplied by 10) 


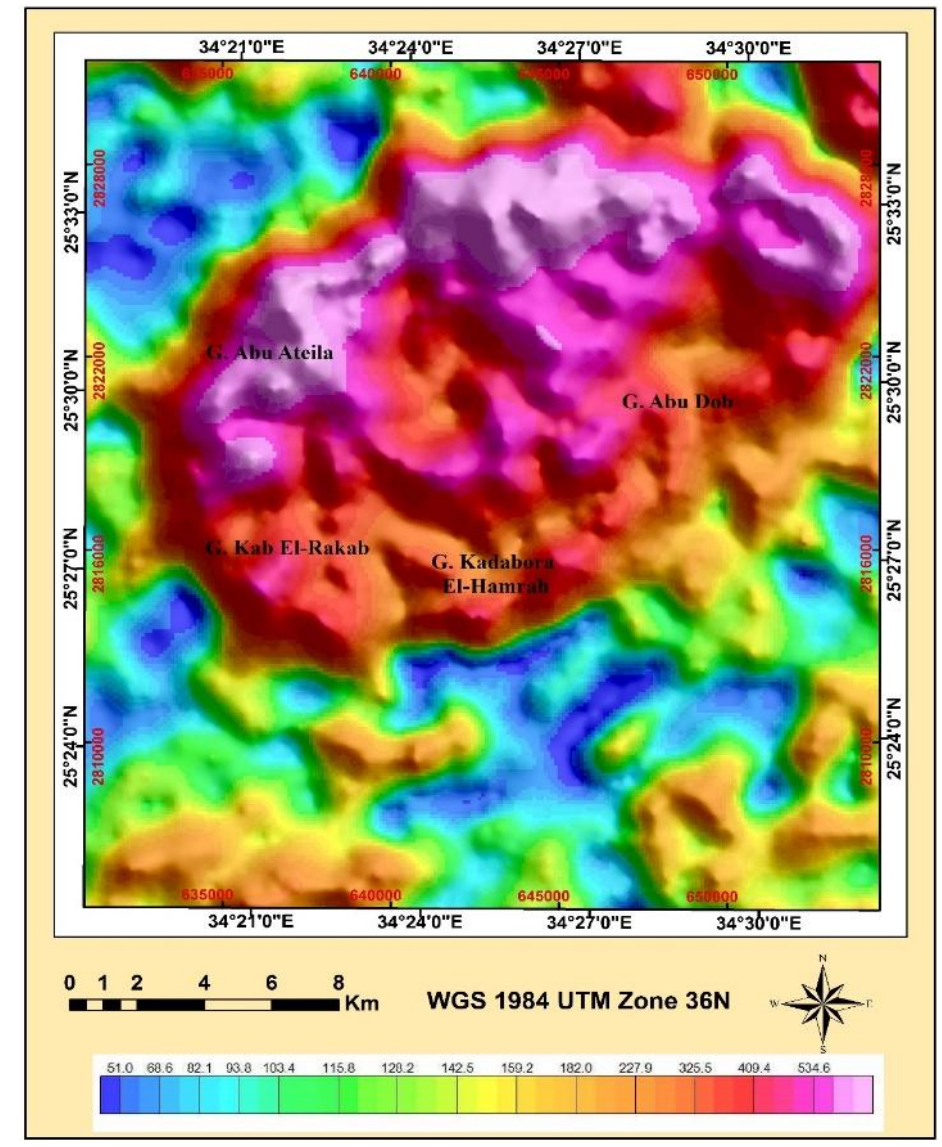

Fig6. Uranium colour shaded map of the studied area, CED, Egypt. (values in ppm multiplied by 10)

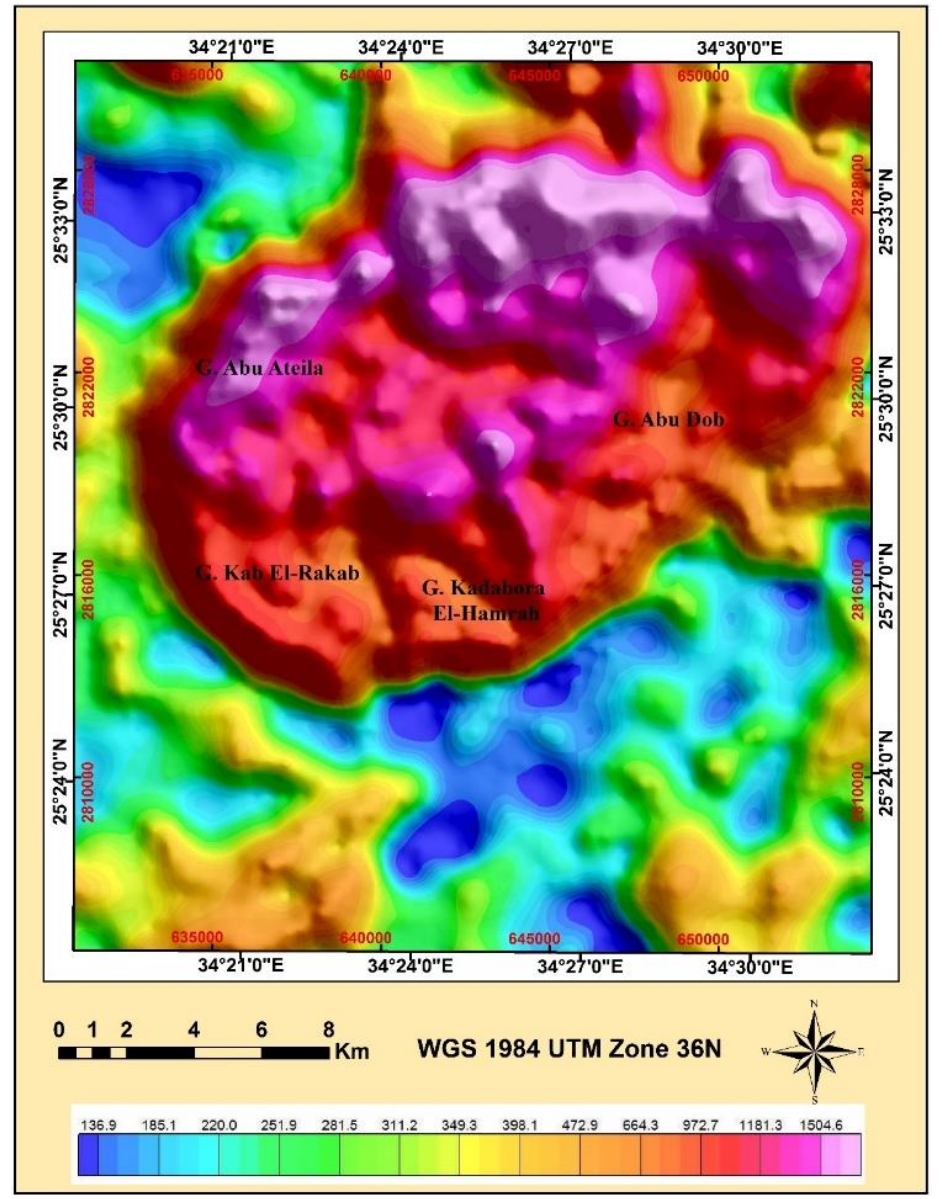

Fig7. Thorium colour shaded map of the studied area, CED, Egypt.(values in ppm multiplied by 10) 


\section{- Ternary Radioelement images}

Through using the resulted four gamma-ray images total count, potassium K40, equivalent uranium (eU) and equivalent Thorium (eTh) several color composite images can be generated by putting three of the four images in the red, green and blue color gun but the standard radioelement colour composite uses K40, eTh and eU as RGB respectively in order to minimize the noise that is usually present in uranium channel (Erdi-Krausz, Matolin et al. 2003). In mineral exploration using ratio images is an extremely helpful tool in lithological discrimination and alteration mineral mapping so, in the present study the following radioelement composite images were generated:

1. $\mathrm{K}, \mathrm{eTh}, \mathrm{eU}=$ ternary radioelement image (Fig. 8).

2. $\mathrm{K}, \mathrm{K} / \mathrm{eTh}, \mathrm{K} / \mathrm{eU}=$ potassium ratio composite image (Fig. 9).

3. eU/K, eU/eTh, eU = uranium ratio composite image (Fig. 10).

4. $\mathrm{eTh}, \mathrm{eTh} / \mathrm{K}, \mathrm{eTh} / \mathrm{eU}=$ thorium ratio composite image $\mathbf{( F i g . ~ 1 1 ) . ~}$

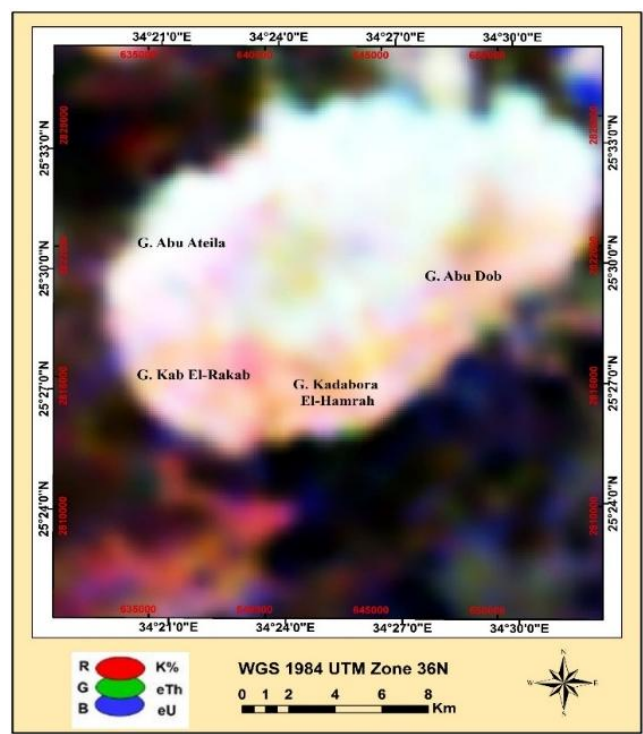

Fig8. Ternary radioelement concentration images of the studied area, CED, Egypt where K\%, eTh and eU in RGB.

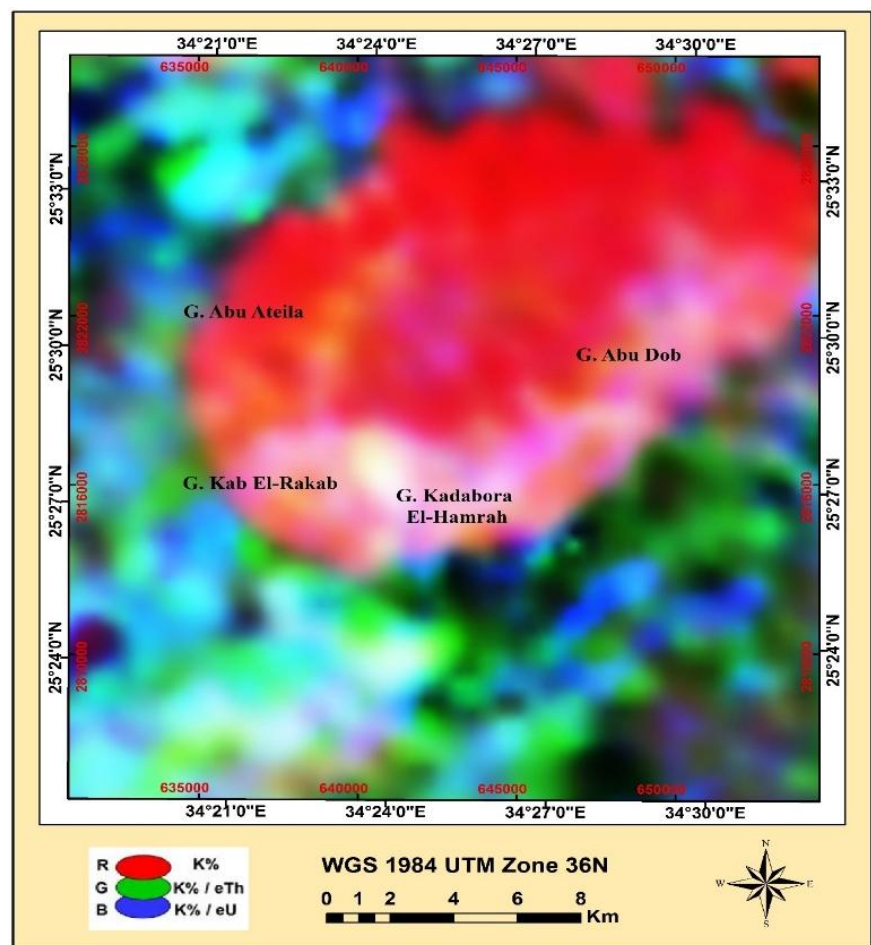

Fig9. Potassium composite ratio image of the studied area, CED, Egypt where K\%, K/eTh and K/eU in RGB. 


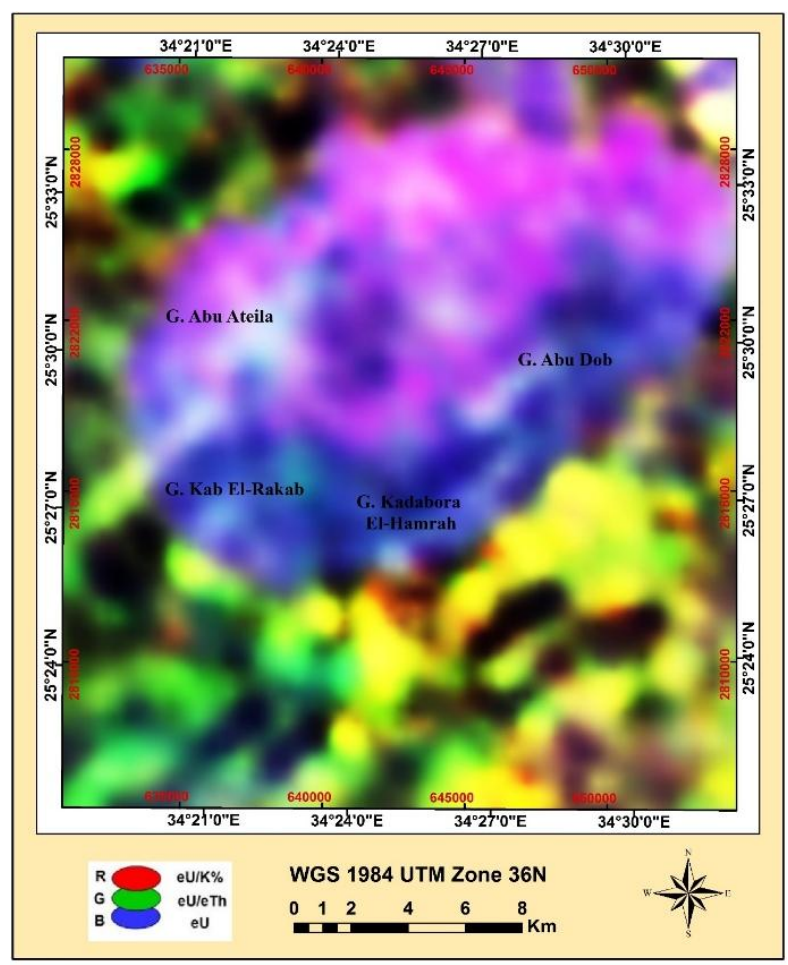

Fig10. Uranium composite ratio image of the studied area, CED, Egypt where eU/K\%, eU/eTh and eU in $R G B$.

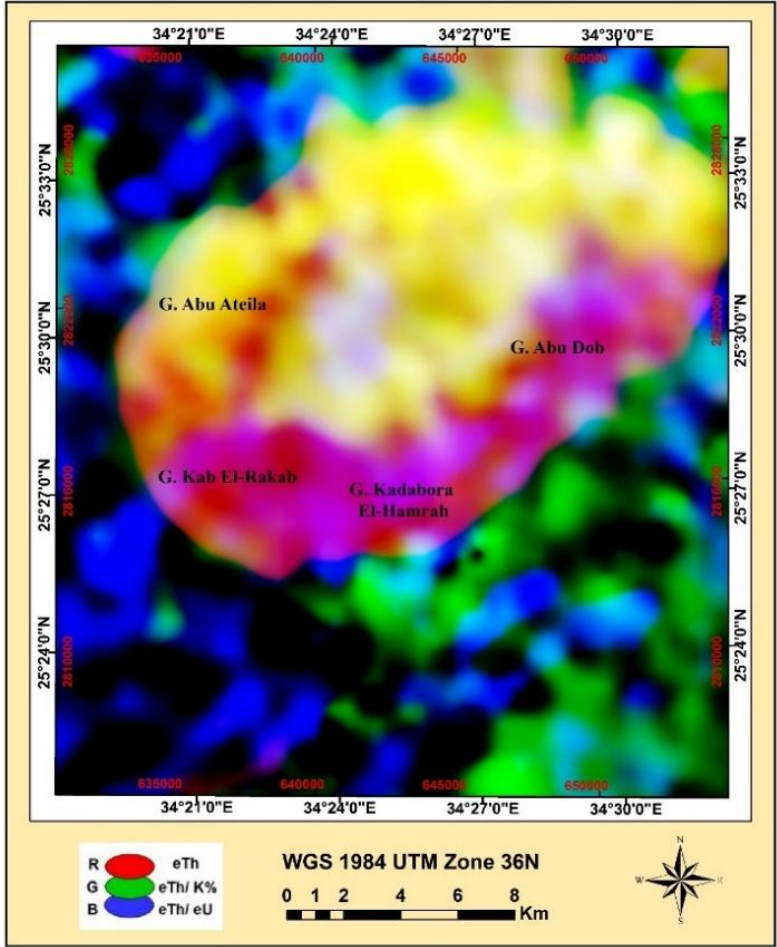

Fig11. Thorium composite ratio image of the studied area, CED, Egypt where eTh, eTh/k\% and eTh/eU in RGB.

\section{- Principal Component Analysis}

The principal component analysis is a statical transformation that is used to produce uncorrelated output bands, to segregate noise components, and to reduce the dimensionality of data sets through deducing a new set of orthogonal axes that have their origin at the data mean and that is moved so the data variance is maximized (Richards 1999).

The first PC band comprises the largest percentage of data variance then the second PC band, and so on. The last PC bands looks noisy because they contain very little variance. In the present study a stack of the three radioelement $\mathrm{K} \%$, eTh and $\mathrm{eU}$ images were made and used as an input to the principal 
component analysis resulting of three bands PC1, PC2 and PC3. (Fig 12) represents the color shaded image generated from the first Principal component PC1.

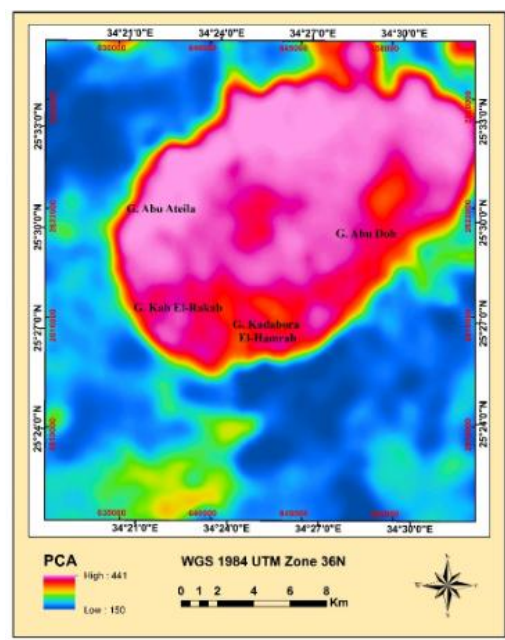

Fig12. Color shaded image of the First PC of the principal components of the studied area, CED Egypt.

\section{- K-Means classification}

K-Means classification is the most common unsupervised classification method which depends on calculating initial class means evenly distributed in the data then repetitively clusters the pixels into the nearest class using a minimum distance technique. Each repetition called iteration in which class means are recalculated and pixels are reclassified with respect to the new means(Tou and Gonzalez 1974).

In the current study a stack of the three radioelement $\mathrm{K} \%$, eTh and eU images was used as an input to K-Means unsupervised classification and 10 was set as a number of classes and iterations (Fig 13) represents the K-means radioelement classified image.

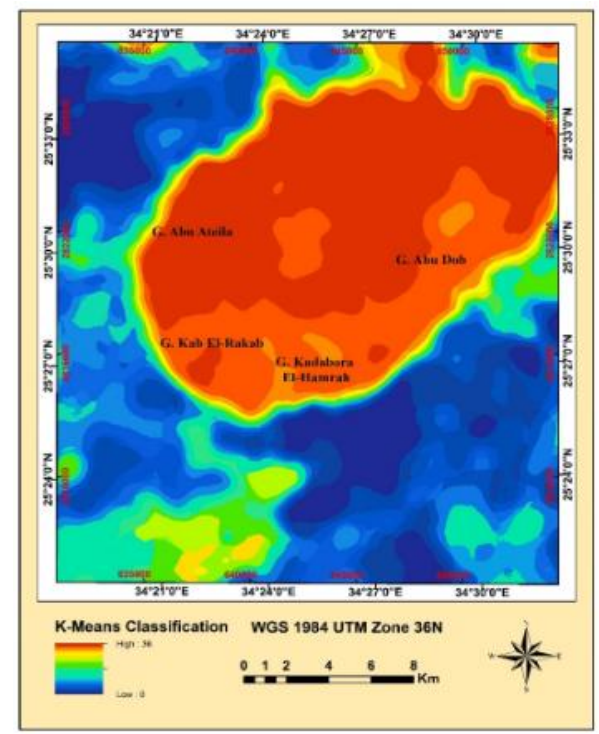

Fig13. K-Means classified image of the studied area, CED, Egypt using three radio elements as the input.

\section{DISCUSSION}

Airborne Gamma-ray Spectrometry is considered a very supportive tool in geological and alteration mineral mapping as $\mathrm{U}, \mathrm{Th}, \mathrm{K}$ distributions in the rocks correlate lithological rock units and the potassic alteration zones associated with uranium mineralization.

Total count map (Fig. 4) the overall gamma-ray radiation ranges from (13.65 to $126.92 \mu \mathrm{R} / \mathrm{h}$ ) while gamma-ray ranges in K\%, eU and eTh images (Figs 5, 6 and 7) between $(3.8,32.17 \%),(13.69,150.46)$ and $(5.1,53.46)$ respectively. The four airborne gamma-ray absolute concentration images Tc, K40, eU and eTh (Figs 4, 5, 6 and 7) merely classify study area into the following gamma-ray ranges: 
1- The highest gamma-ray range represented in magenta which correlates syanogranites located mainly at the upper and lower part of Kadabora pluton with eU concentration between (41-53.46 ppm).

2- The high gamma-ray range represented in Red to orange which correlates monzogranites which located mainly at the central part of Kadabora pluton and south western part of the study area with eU concentration between (33-40.9 ppm). The Intermediate gamma-ray range represented in yellow to green which correlates metagabbros and schist and greywackes which located in the western, southeastern parts of the study area respectively with eU concentration between (32.9-11.5 ppm).

3- The low gamma-ray range represented in cyan to blue which correlates arc metavolcanic and volcanogenic metasediments which are located south of Kadabora pluton and in the northwestern part of the study area with eU concentration between (5-11.6 ppm).

Ternary radioelement concentration image shows (Fig.8) where $\mathrm{K} \%$, eTh, eU as RGB it is noted that Kadabora pluton has the highest concentrations of Th, $\mathrm{U}$ and $\mathrm{K}$ in the study area which represented in very bright color (Fig. 8). The equivalent thorium absolute concentration map (Fig. 7) classifies Kadabora pluton into three sectors; the southern part located SW with a lower concentration in red color, the central part with a medium concentration in deep magenta, and the northern part with higher concentrations in pale magenta.

Ternary radioelement composite ratio images: potassium composite ratio (K\%, K/eTh and $\mathrm{K} / \mathrm{eU})$ (Fig. 9), uranium Composite ratio (eU/K, eU/eTh and eU) (Fig. 10) and thorium composite ratio (eTh, eTh/K and eTh/eU) (Fig. 11), the relative correlation with geological mapping is very clear. The most promising part of the study area in the Northern part of Kadabora pluton which is characterized by high concentrations of uranium, potassium and thorium and that correlates the syanogranite.

Color shaded first Pc image (Fig. 12), the Kadabora pluton is very distinctive with a red to a pink color indicating the high percentages of the three radioelements in comparison with the countryrock. Kadabora pluton appears divided into the northern part with light pink color, central and southern part red color shades. The most promising parts are the northern then the central part of Kadabora pluton that correlate syanogranites and monzogranites respectively.

K-Means Classified image (Fig. 13), the thematic image generated from K-mean unsupervised classification correlates that of the PCA and ratios but it surpasses them in being sharply discriminating high potential radioactive areas from the surroundings more effective than other techniques.

Overlaying structural lineament with pegmatite localities and thresholded PCA first PC (Fig. 14) shows a very high correlation which deeply concludes the presence of structural and lithological controls affecting potential radioactive anomalies.

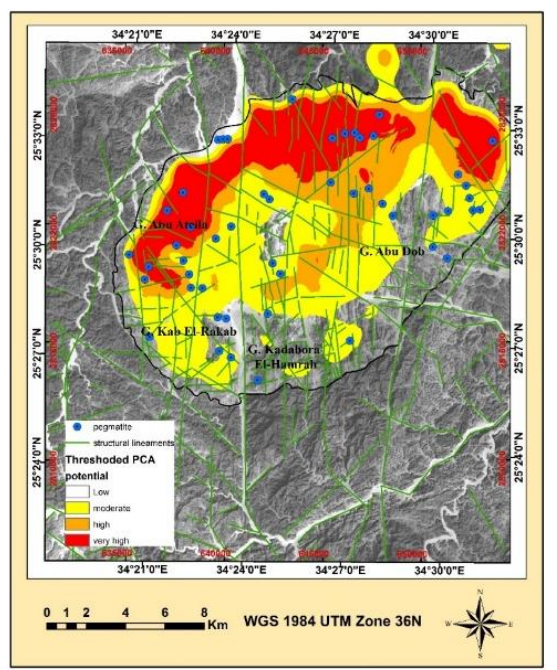

Fig14. Pegmatite localities, structural lineaments and thresholded PC image dropped over Landsat 8 blue band representing the controls affecting potential radioactive localities. 


\section{CONCLUSION}

G. Kadabora batholith is considered the highest radioactive anomaly in the current study area. the Kadabora pluton can be subdivided into three parts Northern, central and southern where the Northern part is the most promising part. Where eU concentration between (41-53.46 ppm). Potential radioactivity was noted to correlate specific structural trends(N-S) and lithological units (Pegmatite, Syanogranite and Monzogranite respectively).

Gamma-ray spectrometry is a very supportive tool in detecting regional radioactive anomaly but further detailed exploration needs finer spatial resolution data.

Principal Component Analysis PCA and K-Mean unsupervised classification represent their effectiveness in discriminating potential radioactive anomaly using the stacked three radioelement images.

\section{REFERENCES}

[1] Ahmed, A. A. (2002). Geology, Petrography and Radioactivity of Kadabora district, Central Eastern Desert of Egypt. Ph.D. Thesis, South Valley Univ., Aswan, Egypt, 214p.

[2] El-Gaby, S., et al. (1984). Tectonic evolution of the basement complex in the Central Eastern Desert of Egypt. Geologische Rundschau, V. 73, No. 3, pp.1019-1036.

[3] EL-Gaby, S., et al. (1988). Geology, evolution and metallogenesis of the Pan-African belt in Egypt. The Pan-African belt of the North East Africa and Adjacent Areas. Vieweg Verlag, Wiesbaden, Germany, V. pp.17-68.

[4] Erdi-Krausz, G., et al. (2003). Guidelines for radioelement mapping using gamma ray spectrometry data. International Atomic Energy Agency (IAEA), Vienna, V. 1363,

[5] Kusky, T. M., et al. (2003). Evolution of the East African and related orogens, and the assembly of Gondwana. Precambrian Research, V. 123, No. 2-4, pp.81-85.

[6] Richards, J. A. (1999). Remote sensing digital image analysis. Springer, 3, pp.161-201.

[7] Stern, R. J. (1994). Arc assembly and continental collision in the Neoproterozoic East African Orogen: implications for the consolidation of Gondwanaland. Annual Review of Earth Planetary Sciences. 22, No.1, pp.319-351.

[8] Stern, R. J. and C. E. Hedge (1985). Geochronologic and isotopic constraints on late Precambrian crustal evolution in the Eastern Desert of Egypt. American Journal of Science. 285, No. 2, pp.97-127.

[9] Tou, J. T. and R. C. Gonzalez (1974). Pattern Recognition Principles. Addison-Wesley Publication Company, Reading, MA, pp.377.

Citation: Gehad M. Saleh, et.al., " Using Airborne Gamma-Ray Spectrometry for Mapping Radioactive Zones in G. Kadabora Area, Central Eastern Desert, Egypt", International Journal of Mining Science (IJMS), vol. 6, no. 2, pp. 1-10, 2020. Available: DOI: http://dx.doi.org/ 10.20431/2454-9428.0602001

Copyright: () 2020 Authors. This is an open-access article distributed under the terms of the Creative Commons Attribution License, which permits unrestricted use, distribution, and reproduction in any medium, provided the original author and source are credited. 